Short Communication

\title{
Occurrence of Malaria in the Local Population of Swat Valley, Pakistan
}

\author{
Hina Habib Syed ${ }^{1}$, Muzafar Shah ${ }^{2 *}$, Shahid Sherzada ${ }^{3}$ and Masroor Elahi Babar ${ }^{1}$ \\ ${ }^{1}$ Department of Biology, Faculty of Science and Technology, Virtual University of \\ Pakistan, Lahore \\ ${ }^{2}$ Center for Animal Sciences and Fisheries, University of Swat, Swat, Pakistan \\ ${ }^{3}$ Department of Fisheries and Aquaculture, University of Veterinary and Animal \\ Sciences, Lahore, Pakistan
}

\begin{abstract}
A B S T R A C T
The present study was carried out in District Swat from January to July, 2017. Blood samples were collected from all age groups patients visiting hospital labs and District Head Quarter Laboratory who were recommended for diagnosis of malaria. About 1050 patients were examined and malaria was detected through microscopy of thick and thin blood smears and rapid diagnostic test of which 118 $(11.24 \%)$ were found to be infected with malaria parasite. Data was also collected sfrom other labs of District Swat which accumulated to a total of 9255 patients, among which $932(10.07 \%)$ patients were found positive for malaria parasite. Male infected were $558(59.87 \%)$ while $374(40.13 \%)$ were female. The collective data showed majority of the infected patients belonged to age group 1-10 years (41.42\%). The least infected were aged above 60 years $(0.86 \%)$. Month wise prevalence was found highest in the month of July $(39.48 \%)$ i.e. summer season and lowest in the month of February $(2.25 \%)$ i.e. winter month. Patients tested for malaria parasite belonged to the following seven (7) Tehsils wherein the rate of positive infected cases in descending order was: Barikot $>$ Kabal $>$ Babuzai $>$ Matta $>$ Khwazakhela $>$ Charbagh $>$ Bahrain. It is concluded from this study that $P$. vivax is the prevalent malaria causing parasite in district Swat. No case of P. falciparum was recorded. Furthermore, male are infected more than female, and malaria is common in children and youth of the area.
\end{abstract}

Article Information
Received 17 December 2018
Revised 24 June 2019
Accepted 11 September 2019
Available online 01 May 2020
Authors' Contribution
HBS collected field data. SS and
MEB designed the experiments. MS
analysed the data. HG wrote the
article.
Key words
Occurrence, Malaria, Khwazakhela,
Bahrain, Swat Valley

$\mathrm{M}$ alaria being disease of the tropics (Hulden et al., 2014) is also prevalent in Pakistan. The majorly affected areas are the provinces of Khyber Pakhtunkhwa, Sindh and Baluchistan along with the tribal areas of the country which are under federal administration. One of the main reasons malaria is prevailing in this area is because of the large masses of stagnant water which provide breeding grounds for Plasmodium (Khattak et al., 2013). Mortality rate due to malaria in 2015 has been recorded as 438,000 globally and about 3.5 million cases have been reported from Pakistan (WHO, 2013). In spite of an established malaria control program running in Pakistan, annual mortality rate of 50,000 per annum due to malaria has been estimated. This is because of frequent floods in the previous years, development of resistance in P. falciparum to Chloroquine and continuous surge of the Afghan refugees to Pakistan who carry the organism P. falciparum is a common species in Afghanistan (Khattak et al., 2013). Annually in Pakistan after a period of monsoon rainfall there is an outburst of malaria resulting in countless deaths. (Nizamani et al., 2006). Malaria cases are reported throughout the year in District Swat but the number of cases drops in winter and

\footnotetext{
Corresponding author: muzafar@uswat.edu.pk 0030-9923/2020/0004-1615 \$ 9.00/0

Copyright 2020 Zoological Society of Pakistan
}

is found more frequent in summer. Among the various Plasmodium Species $P$. vivax is known to have the most devastating effect and is the most predominant species (Oliveira-Ferreira et al., 2010).

The aim of present study: to record symptomatic cases of malarial patient in general population of Swat valley; to carry out a survey on the Lab registered patient for malarial disease in government hospitals and private diagnostic laboratories of District Swat and to correlate the data collected from all the labs in order to find out any relationship among the results.

\section{Materials and methods}

The present study was carried out in District Swat which is located in the north of Khyber Pakhtunkhwa province. Mingora is the main town of district Swat and Saidu Sharif is the District Headquarter. The district is divided into seven tehsils i.e. Babuzai, Bahrain, Barikot, Charbagh, Khwaza Khela, Kabal and Matta (Hamayun et al., 2006).

The study was conducted for a period of 7 months from January to July, 2017. For the current study blood samples were collected from patients visiting the hospital, malaria diagnostic labs and District Head Quarter Hospital Laboratory showing symptoms for malaria disease belonging to all age groups and recommended for blood test for the diagnosis of malaria disease by the physician 
in the hospitals of Swat Valley. The following information (name, gender, age and residence) were gathered on a printed proforma from the local patients.

About 9255 patients were examined for this study and malaria was detected through microscopy of thick and thin blood smears and rapid diagnostic test. Blood samples were collected in a $200 \mu$ EDTA tubes from overall seven tehsils of Swat and rural areas.

Finger tip of the patient was cleaned with Alcohol $(70 \%)$ or methylated spirit and afterwards pricked with a sterilized disposable lancet. For this purpose, we took two clean slides. We used one for smear preparation and the other for blood film. After pricking of the patient fingertip, we discarded the first drop of blood that ooze out from it and place the second or next drop on the slide. Both thick and thin blood smears were prepared and Giemsa stained appropriately on slides and then observed through microscopy under $100 \mathrm{X}$ with oil immersion for the detection of malaria parasite i.e. Plasmodium sp. (Shah et al., 2016). (Clendennen et al., 1995) and was used to identify the type of malaria parasite i.e., $P$. vivax and $P$. falciparum species among the positive samples.

For preparation and staining of thick blood smear on a clean glass slide 3-5 drops of peripheral blood were taken. With the help of another slide a smear was made. The smear length on the slide must be one-third of an inch. Then the slide was left for a few minutes in air to dry. Afterwards the slide was placed upon a staining rack. Giemsa stain was poured on it. For about 10-15 minutes the slide was left to stain. Then the slide was carefully washed. Finally, the stained slide was observed for microscopy with $100 \mathrm{X}$ with oil immersion for the detection of malaria parasite.

For preparation and staining of thin blood smear we placed a single drop of peripheral blood on a slide. We used another slide to make the smear. The smear made should be of 1 inch. It was the left in air to dry. Afterwards methanol was used for 30 seconds to fix the smear. Then on the slide Giemsa stain was poured. For about 10-15 minutes the slide was left to stain. Then we carefully washed the slide and left it for air dry in an upright position. Finally we observed the slide under $100 \mathrm{X}$ with oil immersion for thorough morphological detection of malaria parasite.

For rapid diagnostic test (RDTs) After collection of blood samples in an anti-coagulant tube, $0.5 \mu$ blood was taken and then transferred into the round sample well of the rapid diagnostic test kit (SD Bioline Malaria kit). Afterwards we add assay diluents only 4 drops as instructed by the manufacturer. The presence of two lines after 15 minutes of test checking was considered as positive whereas if only a single control line appeared it as considered as a negative result. The appearance of three lines would indicate the presence of mixed infection of $P$. vivax and $P$. falciparum (Zeb et al., 2015).

\section{Results and discussion}

Table I shows the overall findings of the data collected for at DHQ lab and other labs of District Swat. A total of 9255 patients were examined over a period of seven (7) months (Jan-Jul) among which 932 patients were found positive for malaria parasite showing a prevalence rate of $10.07 \%$. The malaria parasite found was $P$. vivax and no patients suffering from $P$. falciparum was found.

Literature shows $(6.8 \%)$ prevalence of malaria parasite in local population of District Mardan, Khyber Pakhtunkhwa, in the year 2013 (Majid et al., 2016). A study conducted at district Dir detected 324 (39.5\%) out of 821 patients as positive for malaria. It is worth notable that as Dir is warmer as compared to swat hence showing larger number of patients with malaria parasite (Shah et al., 2016). Similarly another study carried out in District Lower Dir, Khyber Pakhtunkhwa, Pakistan in 2011 reported a collection of 3760 blood samples, diagnosis was done using RTD and microscopy, results showed $12.2 \%$ positive cases among which $P$. vivax, $P$. falciparum and mixed species ( $P$. vivax and $P$. falciparum) were found in the ratio of (94.3\%), (3.9\%) and (1.7\%) respectively (Zeb et al., 2015).

Table I shows maximum number of patients tested in the month of July $(24.02 \%)$ and the least number of patients were found in Jan $(0.74 \%)$. Out of the total 932 infected patients, month wise prevalence of malaria parasite in the district was highest in the month of Jul (39.48\%) and lowest in the month of Feb (2.25\%).

Similarly, Muhammad andHussain(2011)also showed maximum prevalence in August $(11.66 \%)$ i.e. summer months than March (3.98\%) i.e. winter months which showed the minimum prevalence rate. Malaria parasite showed more prevalence at the beginning of summer and lower in winter in another study (Khan et al., 2016). July was also reported to be the month showing maximum prevalence of malaria parasite (Ibrahim et al., 2014). $P$. vivax occurrence was reported minimum in January and maximum in June (Ahmad et al., 2013). An investigation was carried out in 20 different localities of District Bolan, Baluchistan, Pakistan, to find out the prevalence of malaria in the general population. The study showed $P$. vivax (86.2\%) and P. falciparum (13.7\%), both parasites also showed seasonal variation with $P$. vivax at peak (91.4\%) and lowest (71.4\%) in January, whereas $P$. falciparum was found at peak $(28.5 \%)$ in January and lowest $(8.5 \%)$ in December (Yasinzai and Kakarsulemankhel, 2009a). The reason behind the maximum prevalence of P.vivax during summer season might be the gradual rise in temperature and humidity hence climatic fluctuation providing the parasite more favorable condition hence bringing a speedy increase in the occurrence of malaria parasite i.e. P. vivax in the district.

Out of the total 932 infected blood samples 558 of 
them were male $(59.87 \%)$ while 374 were female $(40.13 \%)$ (Table I).

Male and female percentage of infection shows similarity to the study of Zeb et al. (2015) that also showed $58.5 \%$ male infection rate to $41.5 \%$ female. Similar high susceptibility rate of male $7.10 \%$ as compared to female $6.52 \%$ was showed during another study (Muhammad and Hussain, 2011). Khan et al. (2016) and Shah et al. (2016) also discussed male being at more risk to malaria than females. A higher rate of infection $(75.9 \%)$ was also shown in a study conducted in the District Ziarat and Sanjavi (Yasinzai and Kakarsulemankhel, 2009b). Another study of Yasinzai and Kakarsulemankhel (2013) at district Panjgur also describes male to be found to be at high risk $78 \%$.

Table I. Total monthly results of District Swat.

\begin{tabular}{lllllll}
\hline Months & $\begin{array}{l}\text { Total tested } \\
\text { n (\%) }\end{array}$ & $\begin{array}{l}\text { Positive n } \\
(\%)\end{array}$ & PV & PF & $\begin{array}{l}\text { Male } \\
\text { +ve }\end{array}$ & $\begin{array}{l}\text { Female } \\
\text { +ve }\end{array}$ \\
\hline Jan & $690(7.45)$ & $22(2.36)$ & 22 & 0 & 13 & 9 \\
Feb & $833(9.00)$ & $21(2.25)$ & 21 & 0 & 12 & 9 \\
March & $919(9.92)$ & $31(3.32)$ & 31 & 0 & 19 & 12 \\
April & $1185(12.80)$ & $56(6.00)$ & 56 & 0 & 32 & 24 \\
May & $1761(19.02)$ & $169(18.13)$ & 169 & 0 & 97 & 72 \\
June & $1642(17.74)$ & $265(28.43)$ & 265 & 0 & 164 & 101 \\
July & $2225(24.04)$ & $368(39.48)$ & 368 & 0 & 221 & 147 \\
Total & 9255 & 932 & 932 & 0 & 558 & 374 \\
\% & & 10.07 & 100.00 & 0.00 & 59.87 & 40.13 \\
\hline
\end{tabular}

PV, Plasmodium vivax; PF, Plasmodium falciparum.

All the patients examined were divided into various age groups i.e., 1-10, 11-20, 21-30, 31-40, 41-50 and above 60 years, the collective data for District Swat showed majority of the infected patients belonged to age group $1-10$ years $(41.42 \%)$, followed by $11-20$ years $(29.51 \%)$ and the least infected age groups were aged above 60 years $(0.86 \%)$ as shown in Table II.

Table II. Age wise patients of District Swat.

\begin{tabular}{llllllllll}
\hline $\begin{array}{l}\text { Age group } \\
\text { (Years) }\end{array}$ & & & & & & & & & \\
& & & & & & & \\
$1-10$ & 6 & 6 & 9 & 17 & 75 & 115 & 158 & 386 & 41.42 \\
$11-20$ & 7 & 3 & 12 & 18 & 49 & 75 & 111 & 275 & 29.51 \\
$21-30$ & 4 & 9 & 7 & 10 & 18 & 34 & 48 & 130 & 13.95 \\
$31-40$ & 2 & 1 & 2 & 3 & 14 & 24 & 31 & 77 & 8.26 \\
$41-50$ & 2 & 2 & 1 & 6 & 5 & 11 & 8 & 35 & 3.76 \\
$51-60$ & 0 & 0 & 0 & 1 & 8 & 4 & 8 & 21 & 2.25 \\
Above 60 & 1 & 0 & 0 & 1 & 0 & 2 & 4 & 8 & 0.86 \\
Total & 22 & 21 & 31 & 56 & 169 & 265 & 368 & 932 & \\
\hline
\end{tabular}

Table III shows the tehsil wise (Barikot, Babuzai, Kabal, Matta, Charbagh, Khwazakhela and Bahrain) result for District Swat. The rate of infection in these tehsils showed maximum infection 584 (62.66\%) from Barikot followed by $113(12.12 \%)$ from Kabal and least number of patients 1 (0.10) from Bahrain. Moreover, among the 9255 tested patients there were also out district patients which were tested for malaria parasite. The tested samples were $331(3.57 \%)$ in which $30(3.21 \%)$ were infected.

Table III. Tehsil wise patients of District Swat.

\begin{tabular}{llllll}
\hline Name Tehsil & Total tested n (\%) & P.V n (\%) & P.F & MIX & Total \\
\hline Barikot & $2973(32.12)$ & $584(62.66)$ & 0 & 0 & 584 \\
Babuzai & $1379(14.90)$ & $104(11.15)$ & 0 & 0 & 104 \\
Kabal & $1612(17.41)$ & $113(12.12)$ & 0 & 0 & 113 \\
Matta & $1973(21.31)$ & $48(5.15)$ & 0 & 0 & 48 \\
Charbagh & $368(3.97)$ & $12(1.28)$ & 0 & 0 & 12 \\
Khwazakhela & $511(5.52)$ & $40(4.29)$ & 0 & 0 & 40 \\
Bahrain & $108(1.16)$ & $1(0.10)$ & 0 & 0 & 1 \\
Other & $331(3.57)$ & $30(3.21)$ & 0 & 0 & 30 \\
Total & 9255 & 932 & 0 & 0 & 932 \\
\% & & 10.07 & 0.00 & 0.00 & 10.07 \\
\hline
\end{tabular}

Rate of positive infected cases in these 7 Tehsils in descending order was:

Barikot $>$ Kabal $>$ Babuzai $>$ Matta $>$ Khwazakhela $>$ Charbagh $>$ Bahrain.

Similar study showed, individuals between ages 2130 years at higher risk of infection to both species (Shah et al., 2016). Another study of Prevalence of malaria parasite in local population of District Mardan, Khyber Pakhtunkhwa, Pakistan in 2013 showed individuals having age between 0 -20 years showed high rate of infection (47.4\%) (Majid et al., 2016). A study in 2001 carried out in District Buner showed $6.86 \%$ cases positive for malaria parasite. Individuals having age 1-10 years were found more susceptible (11.58\%) (Muhammad and Hussain, 2011). A survey was carried out in the religious schools of District Bannu in 2002, to assess the infection of malaria disease, Age wise difference was noted showing results of high to intermediate to low prevalence rate in the following order: $(5.52 \%)$ in $5-9$ years, $(3.37 \%)$ in 10 14 years and $(2.2 \%)$ in 15-19 years (Shah et al., 2018). A survey in district Panjgur, Pakistan during July 2006 to June 2008 wherein a total of 6119 cases were studied among which $2346(38.3 \%)$ were reported as positive, $81.2 \%(n=334)$ and $80 \%(n=860)$ was the rate of infection of the malaria parasite in age groups 1-10 and 11-20, respectively (Yasinzai and Kakarsulemankhel, 2013).

Among the seven tehsils, tehsil Barikot, Kabal and Babuzai are found to be the major infected areas, furthermore, cold areas like Bahrain show less than $1 \%$ infection. Study by (Ali et al., 2013) indicated cases recorded from urban and peri-urban areas were 496 and 1400 respectively which shows peri-urban areas as having higher incidence of malaria as compared to urban areas, $P$. vivax was found to be the dominant specie. A survey was carried out in the religious schools of District Bannu in 
2002, which found that rural areas were found to be having more prevalence $(4.56 \%)$ than urban ones $(2.38 \%)$ (Shah et al., 2018).

In the current study $P$. vivax was found as the prevalent malaria causing parasite in District Swat and No case of $P$. falciparum was recorded. A survey of district Panjgur (considered as among the hottest areas of the Baluchistan province), Pakistan, was conducted from clinics and hospitals which suggested a higher rate of infection by malaria majorly through parasite of $P$. vivax and also minor but serious threat can also be posed by P. falciparum especially cerebral malaria (Yasinzai and Kakarsulemankhel, 2013). Similarly District Mardan, shows $(92.56 \%)$ positive cases of $P$. vivax, hence found dominant specie in comparison to $P$. falciparum $(7.44 \%)$ (Majid et al., 2016). A one year study conducted from October 2013 to September 2014 in district Dir Lower showed presence of $P$. vivax (30.1\%) and $P$. falciparum $(9.4 \%)$ and no cases of mixed specie infection were found (Shah et al., 2016). A study in 2001 conducted at District Buner recorded $6.86 \%$ cases as positive for malaria parasite. No mixed infections were observed and $P$. vivax and $P$. falciparum was found in the range of $5.78 \%$ to $1.08 \%$, respectively (Muhammad and Hussain, 2011). Similar findings were reported in a survey carried out in the religious schools of District Bannu in 2002, and found only infection caused by $P$. vivax parasite (Shah et al., 2018). Similarly an investigation carried out in 20 different localities of district Bolan, Baluchistan, also showed majority of the patients were infected by $P$. vivax $(86.2 \%)$ and a few from P. falciparum (13.7\%) (Yasinzai and Kakarsulemankhel, 2009a). A study in 2009-2011 in the public and private labs of Karachi, showed $78.6 \%$ of cases of $P$. vivax and also a few cases of $P$. falciparum (Jamal et al., 2014). A survey conducted in 2006-2008 in District Lasbella of Pakistan found P. vivax was in 860 (65.5\%) patients and 451 (34.4\%) patients were found with $P$. falciparum. Hence, $P$. vivax was concluded as the dominant specie (Yasinzai and Kakarsulemankhel, 2012).

\section{Acknowledgments}

The authors are grateful to DHQ lab and other hospital labs Swat for providing lab facilities for sample collection for the present study.

\section{Statement of conflicts of interest}

The authors declare no conflicts of interest.

\section{References}

Ahmad, T., Hussain, A. and Ahmad, S., 2013. Int. J. Technol. Scient. Res., 2: 199-202.

Ali, I., Munir, S., Sherwani, S.K., Rehman, F.U., Jamal, Q., Abbas, M.N., Khan, A. and Anees, M., 2013. FUUAST J. Biol., 3: 81-85.
Clendennen, T.E., Long, G.W. and Baird, J.K., 1995. Trans. R. Soc. trop. Med. Hyg., 89: 183-184. https:// doi.org/10.1016/0035-9203(95)90486-7

Hamayun, M., Khan, S.A., Sohn, E.Y. and Lee, I.J., 2006. Lyonia, 11: 101-113.

Hulden, L., McKitrick, R. and Hulden, L., 2014. J.R. Stat. Soc. Ser. A (Stat. Soc.), 177: 725-742. https:// doi.org/10.1111/rssa.12036

Ibrahim, S.K., Khan, S. and Akhtar, N., 2014. World J. med. Sci., 11: 478-482.

Jamal, A., Tajjamul, A., Shakeel, M., Ali, Q.U.A. and Abdullah, F.E., 2014. Annls Abbasi Shaheed Hosp. Karachi med. Dent. Coll., 19: 73-78.

Khan, A.Q., Ali, I., Imran, M., Yaseen, M., Abbas, S.Z., Mufti, F.U.D. and Ali, G., 2016. Profess. med. J., 23: 553-558. https://doi.org/10.17957/TPMJ/16.3189

Khattak, A.A., Venkatesan, M., Nadeem, M.F., Satti, H.S., Yaqoob, A., Strauss, K., Khatoon, L., Malik, S.A. and Plowe, C.V., 2013. Malaria J., 12: 297.

Majid, A., Rehman, M., Ahmad, T., Ali, A., Ali, S. and Ali, S., 2016. World J. Zool., 11: 63-66.

Muhammad, N. and Hussain, A., 2011. J. Postgrad. med. Inst. (Peshawar-Pakistan), 17: 75-78.

Nizamani, A., Kalar, N. and Khushk, I., 2006. J. Liaquat Univ. med. Hlth. Sci., 5: 76-83.

Oliveira-Ferreira, J., Lacerda, M.V.G., Brasil, P., Ladislau, J.L.B., Tauil, P.L. and Ribeiro, C.T.D., 2010. Malaria J., 9: 115. https://doi. org/10.1186/1475-2875-9-115

Shah, H., Khan, R., Naz, F., Haseeb, A., Jan, A. and Ullah. R., 2016. J. Ent. Zool. Stud., 4: 1211-1215.

Shah, M., Ali, M., Mehmood, S.A., Ahmad, S., Muhammad, K., Alam, I. and Saeed, K., 2018. Punjab Univ. J. Zool., 33: 54-65. https://doi. org/10.17582/pujz/2018.33.1.54.56

Snow, R.W., Guerra, C.A., Noor, A.M., Myint, H.Y. and Hay, S.I., 2005. Nature, 434: 214. https://doi. org/10.1038/nature03342

WHO. World malaria report 2013. World Health Organization, 2014. Accessed January 08, 2017. http://www.who.int/malaria/publications/world malaria_report_2013/wmr2013no_profiles. pdf?ua $=1$.

Yasinzai, M.I. and Kakarsulemankhel, J.K., 2009a. Biologia (Pakistan), 55: 43-50.

Yasinzai, M.I. and Kakarsulemankhel, J.K., $2009 \mathrm{~b}$. Pakistan J. Zool., 41: 475-482.

Yasinzai, M.I. and Kakarsulemankhel, J.K., 2012. Pakistan J. med. Sci., 28: 167-170.

Yasinzai, M. I. and Kakarsulemankhel, J. K., 2013. J. Pak. med. Associ., 63: 313-316.

Zeb, J., Khan, M.S., Ullah, N., Ullah, H., Nabi, G. and Aziz, T., 2015. World J. Zool., 10: 147-152. 